\title{
Energia Solar: Análise Comparativa quanto ao Nível de Conhecimento, Utilização e Importância Sobre a Ótica de Moradores de dois bairros da Cidade de Juazeiro do Norte - CE
}

\author{
Jéssica Raissa Lima da Silva ${ }^{1}$; Manoel Leal Costa Netto ${ }^{2}$
}

\begin{abstract}
Resumo: O estudo abordado irá mostrar a importância da energia solar, pois ela é considerada uma forma alternativa e limpa de geração de energia, sem causar queimas ou outro prejuízo ao ecossistema. O sol é fonte de energia renovável, o uso deste tipo de energia é uma das alternativas mais favoráveis. Nos dias atuais vários países procuram usar as fontes de energias alternativas e renováveis, com o intuito de substituir pelas fontes tradicionais devido ser um tipo de fonte energética poluidora no qual causa muitos danos ao meio ambiente interferindo o presente e as futuras gerações. O objetivo desse projeto é mostrar os benefícios da energia solar de análise comparativa quanto ao nível de conhecimento, utilização e importância sobre a ótica de moradores de dois bairros da cidade de Juazeiro do Norte- CE. O método utilizado para realização desse estudo tratou-se de uma pesquisa de caráter exploratória, com abordagem quantitativa, tendo como instrumento de coleta um questionário semiestruturado. Os resultados alcançados foi o conhecimento de clareza dos moradores dos dois bairros mencionados quanto a utilização e importância da Energia Solar.
\end{abstract}

Palavras-chave: Energia. Meio ambiente. Sustentável.

\section{Solar Energy: Comparative Analysis of the Level of Knowledge, use and Importance on the Residents Perspective of Two Districts of the City of Juazeiro do Norte in Ceará}

\begin{abstract}
This study will show the energy importance as it's considered to be an alternative and clean way of generating energy without causing burns or other damages to the ecosystem. The sun is a source of renewable energy. Using this energy type is one of the most favorable alternatives. Nowadays, many countries try to use renewable and alternative energy sources to substitute traditional sources because it's a type of polluting energy source that causes several damages to the environment, interfering with present and future generations. The objective of this project is to show the benefits of comparative solar energy as to the level of knowledge, use and importance on the optics of residents of two districts of the city of Juazeiro do Norte - CE. The method used to perform this study was an exploratory research, with a quantitative approach, having as a collection instrument a semi-structured questionnaire. The results achieved were the knowledge of clarity of the residents of the two districts mentioned regarding the use and importance of Solar Energy.
\end{abstract}

Keywords: Energy. Environment. Sustainable.

\footnotetext{
${ }^{1}$ Graduanda no Curso de Administração do Centro Universitário Doutor Leão Sampaio - Unileão jraissa.lima@ hotmail.com

2 Professor Orientador do Centro universitário Doutor Leão Sampaio, Mestre em engenharia agrícola, Contato: manoel@leaosampaio.edu.br.
} 


\section{Introdução}

Atualmente muitas empresas tem procurado utilizar vários meios eficazes visando destacar no mercado dentre eles a implementação de sustentabilidade ambiental. Com a implementação do sistema de energia solar permite economizar na conta de luz, além disso, permite que utilize a luz solar visando criar sua própria energia elétrica.

O uso de energia solar está aumentando de forma contínua. Entre os diversos tipos de energias alternativas, esta é considerada uma fonte de energia renovável e que traz diversos benefícios, ela é que mais recebe investimento em crescimento de maneira contínua anualmente. (PORTO, 2007)

A energia elétrica obtida do sol é bastante proveitosa para as pessoas que investirem neste tipo de energia, pois além de não ser poluente, ela pode ser utilizada não apenas para ser transformada em energia mecânica para mover máquinas, mas também é usada para funcionar diversos aparelhos dentre eles relógios, celulares, geladeiras, ar condicionado e dentre outros. (BAIRD, 2002)

É importante relatar que, a energia solar tem grande relevância na preservação do meio ambiente, por que possui diversos benefícios com relação a outras fontes de energia, pois além de ser usada no funcionamento de diversos equipamentos, ela não é poluente, razão para ajudar de forma significativa para o desenvolvimento sustentável.

Sendo assim, diante do exposto, mencionado que a sustentabilidade está ligada ao desenvolvimento econômico e material, porém sem maltratar o meio ambiente, utilizando os recursos precisos naturais de maneira correta visando diminuir os diversos tipos de poluição. (BAIRD, 2002)

A energia solar tem grande contribuição para o desenvolvimento sustentável, porque os instrumentos utilizados na sua realização, mudança e distribuição são considerados resistentes, sendo que inicialmente o investimento é muito alto, todavia, possui baixo investimento para manter, motivo para este tipo de energia ser mais propícia para o futuro.

O desenvolvimento sustentável exibe um papel social a proporção que colabora no meio ambiente com o propósito que os recursos naturais precisos para conforto e tranquilidade da comunidade sejam conservados. (BAIRD, 2002).

Partindo dessa reflexão levanta-se a seguinte pergunta de pesquisa: Quais os benefícios percebidos a partir da implementação do uso da energia solar?

Acredita-se que a energia solar tem grande relevância na conservação do meio ambiente. 
A energia solar implantada nas empresas tem como benefício à obtenção da economia de forma significativa.

Comparar a percepção das pessoas moradoras de dois bairros da Cidade de Juazeiro do Norte - CE quanto ao nível de conhecimento, utilização e a importância do uso de Energia Solar.

- Mostrar a importância da energia solar apontando assim os benefícios percebidos.

Atualmente os diversos problemas ambientais provocados pelo uso de energias não renováveis, associados a falta dessas fontes, têm mostrado grande motivação e interesse pelo uso de fontes alternativas de energia, como é o caso da energia solar. (JARDIM, 2007).

O estudo tem como relevância tanto para o conhecimento pessoal bem como para os acadêmicos e a sociedade em geral, pois trará informações quanto a importância da energia solar, visto que ela é uma das ações sustentáveis mais propícia no combate contra o desgaste do meio ambiente, porque é renovável e não é poluente.

A presente pesquisa também servirá como embasamento para se desenvolver novos estudos acadêmicos relacionados à energia solar, por exemplo a economia sustentável, que é um tema de fundamental importância para as organizações e para a sociedade, mediante os diversos benefícios atingidos com o desenvolvimento sustentável, a conservação das fontes de recursos naturais, porque com esse modelo de desenvolvimento as empresas começam a procurar maneiras de produção ou fontes de recursos de modo que não seja difícil e não prejudique o meio ambiente ou possam provocar prejuízos inconvertíveis.

\section{Conceito e Importância da Energia Solar}

A energia solar é aquela resultante do sol (energia térmica e luminosa), ela é obtida por painéis solares, construídos por células fotovoltaicas, e convertida em energia elétrica ou mecânica. Este tipo de energia solar pode também ser usado nas casas, visando o aquecimento da água. (BAIRD, 2002)

A esse respeito é importante enfatizar que, nos dias atuais tem aumentado o número de pessoas que buscam o abastecimento da energia solar de forma contínua, devido ser considerado uma alternativa renovável e não poluente, dentre outras vantagens que ajuda o cidadão a obter economia. Sendo que, a princípio o investimento é muito elevado com equipamentos de captação e transformação, mas com passar do tempo obterá retornos significativos (JARDIM, 2007). 
É mediante da energia do Sol que se dá a exalação, início do ciclo das águas, que permite a barragem e posteriormente o início da formação de eletricidade (hidroeletricidade). A radiação solar propicia a movimentação atmosférica provocando a geração dos ventos. (BAIRD, 2002).

É importante destacar que, a produção de energia solar é considerada mais realizável em lugares como o Brasil, por ser um País que possui raios solares maiores praticamente no ano inteiro. Para conseguir a produção de energia elétrica é preciso a utilização de dois sistemas, são eles: o heliotérmico e o fotovoltaico. (BAIRD, 2002)

Cabral (2012) comenta sobre os dois tipos de sistema afirmando que, "O heliotérmico é um tipo de sistema em que a irradiação é transformada a princípio em energia térmica e após em elétrica. Já o sistema de fotovoltaico é diversificado do heliotérmico, pois a irradiação solar é transformada de forma direta em energia".

Ressalta-se que a energia solar tem grande relevância na conservação do meio ambiente devido não poluir, não ajudar para o efeito estufa, além de ser indispensável a presença de geradores para a produção de energia elétrica. Nesse contexto é importante destacar a importância do sistema de heliotérmico e do fotovoltaico, ambos tem a função de captação de energia. (CABRAL, 2012)

A implantação da energia solar nas casas ou empresas traz inúmeros benefícios, sendo que há também algumas desvantagens, dentre elas, a oscilação produzidas conforme com o clima e não há produção no período da noite, geralmente este tipo de energias não são muito favoráveis quando correlatada aos combustíveis fósseis, além da energia hidrelétrica e a biomassa, áreas em altitudes altas elas não são muito eficazes devido o clima não ser favorável por vaus do inverno (PORTO, 2007).

O emprego da energia solar tem suas vantagens e desvantagens, todavia esta fonte de energia solar é considerada vital, pois é considerado modelo de energia renovável, mas é importante procurar e aproveitar esta fonte de energia, pois ela traz diversos benefícios, além de auxiliar para o desenvolvimento sustentável (JARDIM, 2007).

Entretanto, é importante enfatizar que a energia solar, é uma fonte de energia que pode ser muito aproveitada, pois possui ótimas capacidades de produção, porém dentre as fontes renováveis, este tipo de energia está em realce, por que não poluir o meio ambiente, além de ser uma fonte renovável e inesgotável, pois proporciona uma maior confiança e por diminuir os gastos ao passar do tempo. 


\section{Benefícios da Energia Solar}

A energia solar é usada em lugares mais ensolarados, isolados e secos. No país de Israel este tipo de energia é utilizado por uma fatia de pessoas bem considerada correspondendo a $70 \%$ das casas com uso de coletores solares. No Brasil, o uso deste tipo de energia está aumentado de forma contínua, especialmente no que desrespeito o coletor direcionado para aquecimento de água (ANEEL, 2008).

\footnotetext{
Este tipo de energia em vários benefícios para o meio ambiente dentre eles: Fonte de energia limpa e renovável; $\mathrm{O}$ emprego de painéis solares nas residências ou instituições contribui para a luta as transmissões de gases do efeito estufa; É um tipo de energia livre e produtível. Diminui o vício dos combustíveis fósseis. (LOPES, 2011, p. 135)
}

Entretanto, a energia solar é uma ótima alternativa, pois proporciona inúmeros benefícios dentre eles a obtenção da economia de forma significativa mesmo sendo em longo prazo, pois o custo para implantação é muito elevado. Além disso, é um tipo de energia menos poluente e agressivo ao meio ambiente, porque representa uma fonte de energia pura e que está sempre se renovando de forma constante, no qual melhora a qualidade de vida do ser das pessoas. (LOPES, 2011)

\section{Conceito de Sustentabilidade}

Ao defrontar-se com os diversos dilemas ambientais da situação atual, o tema sustentabilidade ganhou foco pelo motivo de ser um assunto que a cada dia está se expandindo, porém chegam ao ponto que atitudes para mudar os impactos ambientais causados pelas pessoas se tornam graves em diversos locais.

A sustentabilidade é a qualidade de alguma coisa que precisa conservar de forma contínua, ou estável, por certo tempo (BACHA, 2010)

Morim (2000) destaca que a sustentabilidade está interligada com o desenvolvimento material e econômico sem prejudicar o meio ambiente, usando os recursos cabíveis naturais de forma correta de modo que eles possam permanecer futuramente.

A esse respeito pode-se perceber que o desenvolvimento sustentável apresenta a sustentabilidade nos diversos segmentos, principalmente no meio ambiente, porque este é 
produzido recursos primordiais ao sustento das pessoas e necessitam ser sustentáveis a fim de suprir as reais necessidades básicas do ser humano, porém sem prejudicar o futuro das pessoas.

As práticas sustentáveis são consideradas um dos caminhos para conservar a qualidade de vida de todas as pessoas do presente e do futuro. Pequenas ações podem fazer a diferença, como manuseio sustentável de alimentos, água, lâmpadas e dentre outros (BACHA, 2010).

Ressalta-se que, as pessoas precisam adotar práticas sustentáveis no meio em que vive, pois pequenas ações podem resultar em diversos benefícios no qual pode ajudar de forma significativa a conservar a qualidade de vida de todas as pessoas tanto no presente como também das futuras gerações.

Abramovay (2012) comenta que uma sociedade pode ser reconhecida como sustentável a partir do momento que todos os cidadãos possam ter objetivos que possam ser atendidos, assegurando o grau de satisfação aos indivíduos.

Diante disso, que todo ser humano precisa se conscientizar pelo emprego das práticas sustentáveis, uma vez que os efeitos provocados contra o meio ambiente têm como consequência vários danos à saúde tanto dos indivíduos como também dos animais.

No meio social uma empresa pode ser vista como sustentável quando se organiza e tem conduta de modo que ela, mediante das gerações, obtém segurança a vida das pessoas e dos biossistemas no meio em que vive (ABRAMOVAY, 2012)

A esse respeito, muitas empresas têm adotado práticas sustentáveis, porque se preocupam com os fatores que estão ligados a sustentabilidade. Tais ações dessas empresas têm como resultado o seu crescimento no mercado, além de uma imagem positiva dos clientes a organização (MORIM, 2000).

Sendo assim, é importante explanar que, as empresas que desejam prosperar e exibir valor aos seus consumidores, elas precisam implementar ações de preservação ao meio ambiente, o qual tem como benefício um ambiente mais agradável e harmonioso entre todos os liderados que fazem parte da organização, além disso a empresa consegue obter lucros de modo a fomentar o crescimento organizacional.

\section{Conceito e Causas ao Meio Ambiente}

É possível perceber, diariamente, que o planeta Terra passa por uma crescente degradação decorrente dos problemas ambientais e sociais provocados pelas ações humanas, como também da escassez de políticas adequadas ou aplicação de planos governamentais que 
atingem diretamente o meio ambiente, como destacam Veloso e Agustinho (2017). Posto isso, compreende-se como meio ambiente o agrupamento de diversos elementos, sejam eles naturais (água, ar, energia), artificiais (espaço urbano) e culturais (patrimônio artístico, paisagístico, histórico, entre outros), ao passo que todos eles colaboram para o equilíbrio vital da humanidade (VELOSO; AGUSTINHO, 2017).

Field e Field (2014) tecem comentários a respeito da chamada economia ambiental, que se relaciona diretamente com a vontade humana e os recursos naturais e ambientes disponíveis na sociedade, visando analisar como as pessoas refletem sobre o uso de tais recursos de maneira que seja possível a destruição ou valoração do meio ambiente. Diante disso, os autores afirmam que a economia ambiental, além de retratar a situação ambiental e suas modificações, traz a ideia de também depreender os motivos para a existência e permanência dessas condições, como ainda de que forma a sociedade pode colaborar com melhorias e mudanças significativamente positivas.

\section{Recursos Naturais}

Para entender o funcionamento do meio ambiente, é preciso considerar o que são os recursos naturais. Barbieri $(2011$, p. 6) os conceitua como sendo "bens e serviços originais ou primários dos quais todos os outros dependem". Ou seja, é tudo aquilo que é produzido, convertido ou transformado da natureza para garantir a satisfação de necessidades humanas, englobando, como citado anteriormente, componentes físicos e biológicos, tais como solo, plantas, animais e outros que podem vir a ter utilidade e sejam acessíveis à manutenção da vida humana. Por outro lado, tendo em vista que o meio ambiente é exatamente uma condição para que seja possível a vida, esses componentes são dados como recursos naturais. $\mathrm{O}$ autor salienta que eles não podem ser analisados e entendidos separadamente, posto que um sofre a influência do outro e são dependentes entre si.

\section{Recursos Renováveis}

Enquanto isso, existem ainda os recursos renováveis e não renováveis. Os primeiros são assim denominados pela possibilidade de serem obtidos de forma indefinida de mesma fonte, não se esgotando e podendo, como seu próprio nome diz, ser renovado rapidamente. Já os recursos não renováveis são finitos, ou seja, como consequência do seu uso constante, em 
algum momento, vão acabar. Barbieri (2011) defende que tal classificação, mesmo que muito utilizada, não deve ser tomada como garantida. O modo como o ser humano usa os recursos e o tempo com que eles são empregados vão definir se eles são ou não renováveis. O autor usa como exemplo a energia solar que recebe o planeta Terra e outros inúmeros recursos que, apesar de serem renováveis, podem ter um limite conforme estão sendo usados ou de acordo como a natureza reage às modificações naturais e feitas pelo homem.

\section{Metodologia}

O tipo de pesquisa utilizado para o desenvolvimento desse estudo foi inicialmente através de fontes bibliográficas. Tendo como método comparativo, que conforme Lakatos e Marconi (2011, p.92) permite analisar o dado concreto, deduzindo do mesmo os elementos constantes, abstratos e gerais. Foi realizada uma pesquisa de opinião com pessoas dos bairros Lagoa Seca e Pirajá da Cidade de Juazeiro do Norte - CE.

Quanto à abordagem trata-se de uma pesquisa quantitativa básica, que de acordo com Lakatos e Marconi (2011, p. 269), "caracteriza-se pelo emprego da quantificação tanto nas modalidades de coleta de informações quanto no tratamento delas por meio de técnicas estatísticas, desde as mais simples como porcentual, média, desvio-padrão, às mais complexas como coeficiente de correlação, análise de regressão etc" (Richardson,1999, p.269 apud Lakatos e Marconi).

A pesquisa exploratória busca apenas levantar informações sobre um determinado objeto, delimitando assim um campo de trabalho, mapeando as condições de manifestação desse objeto (SEVERINO, p. 123). A pesquisa foi realizada pela população de forma comparativa nos bairros Lagoa Seca e Pirajá. Nessa pesquisa o instrumento para coleta de dados será um questionário semiestruturado. 


\section{Análise e Discussões dos Resultados}

\section{Gráfico 1 Sexo}

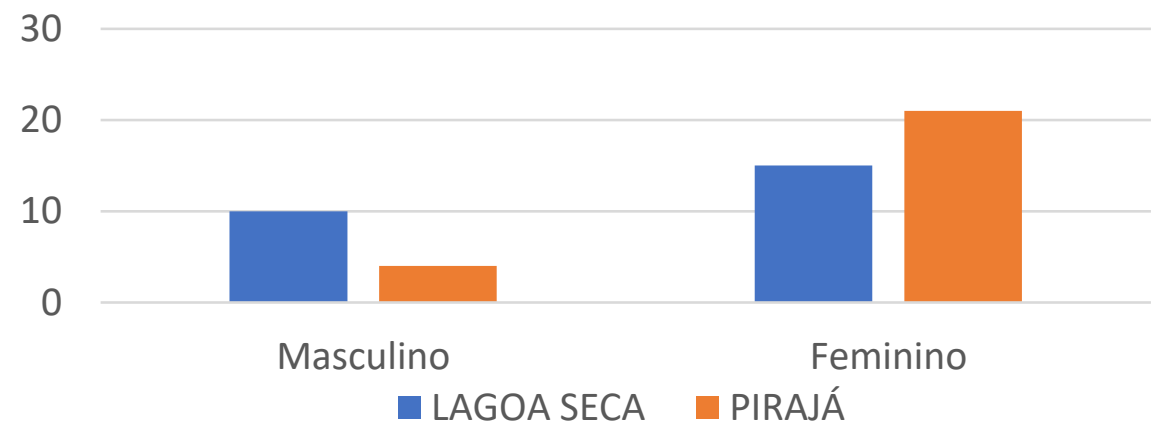

Fonte: Dados da Pesquisa (2018)

Gráfico 1 relata a soma total de participação no questionário, divididos em masculino e feminino. Visto como maior percentual do sexo feminino com total de 21 pessoas do bairro Pirajá e 15 pessoas do bairro Lagoa Seca.

Gráfico 2 Relação das idades.

20

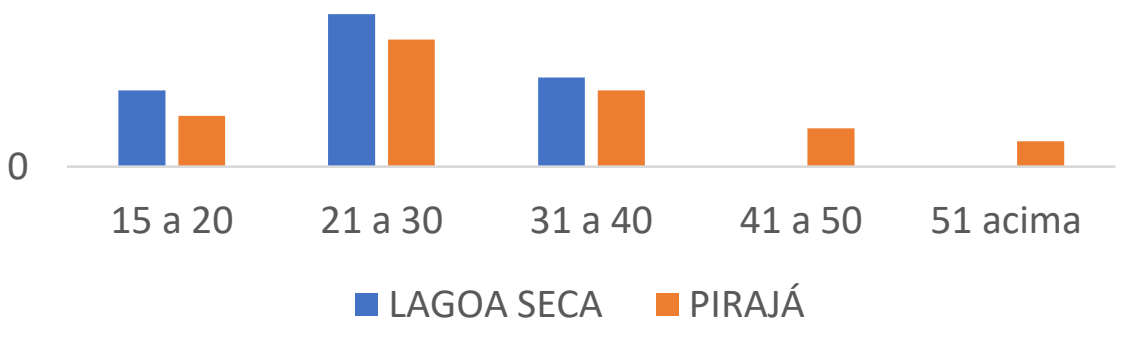

Fonte: Dados da Pesquisa (2018)

Observa-se a relação das idades simultaneamente diferentes. Com total de 22 pessoas marcaram na idade entre 21 a 30 anos, sendo 12 do bairro Lagoa Seca e 10 pessoas do bairro Pirajá, outro total de 10 pessoas marcaram entre 15 a 20 anos, sendo 6 pessoas do bairro Lagoa Seca e 4 pessoas do bairro Pirajá. Outro total de 13 pessoas marcaram de 31 a 40 anos, sendo 7 pessoas do bairro Lagoa Seca e 6 pessoas do bairro Pirajá. Próximo com total de 3 pessoas marcaram 41 a 50 anos, sendo do bairro do Pirajá e Lagoa Seca não houve 
nenhum. Último com total de 2 pessoas marcaram de 51 anos acima, sendo os 2 dos bairros Pirajá e Lagoa Seca não houve nenhum.

Gráfico 3 Relação de escolaridade quanto à conhecimentos específicos.

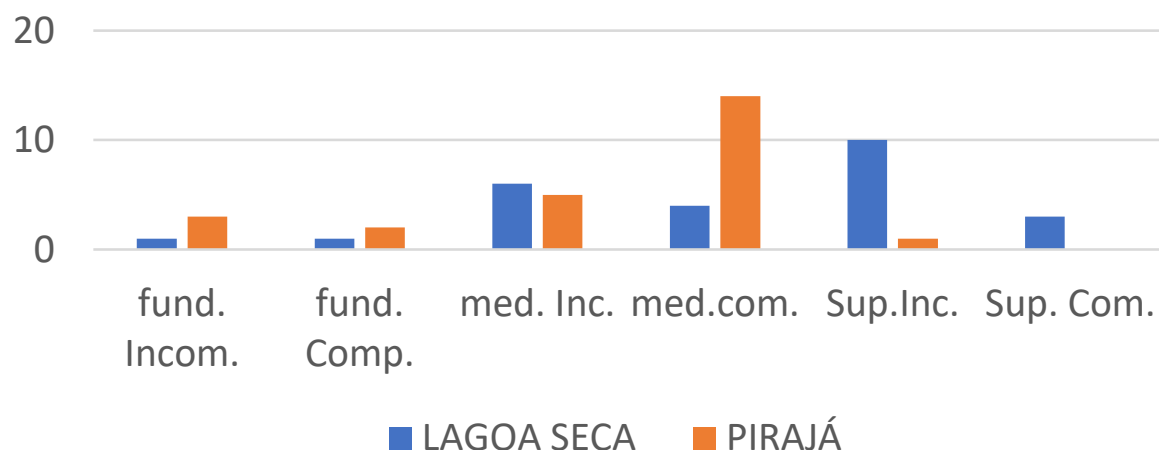

Fonte: Dados da Pesquisa (2018)

Relação de escolaridade, quanto aos conhecimentos específicos sobre assuntos abordados no questionário, assim como, Energia Solar. Percentual com total de 4 pessoas marcaram nível fundamental incompleto, sendo 3 pessoas do bairro Pirajá e somente 1 pessoa do bairro Lagoa Seca. Outro com total 3 pessoas marcaram nível fundamental completo, sendo 2 pessoas do bairro Pirajá e somente 1 pessoa do bairro Lagoa Seca. Outro total com 11 pessoas marcaram nível médio incompleto, sendo 5 pessoas do bairro Pirajá e 6 pessoas do bairro Lagoa Seca. Outro total com 18 pessoas marcaram nível médio completo, sendo 14 pessoas do bairro Pirajá e 4 do bairro lagoa Seca. Outro total com 11 pessoas marcaram nível superior incompleto, sendo somente 1 pessoa do bairro Pirajá e 10 do bairro Lagoa Seca. Último total com 3 pessoas marcaram nível superior completo, sendo 3 pessoas do bairro Lagoa Seca e não houve nenhum do bairro do Pirajá.

Gráfico 4 Fonte de Renda.

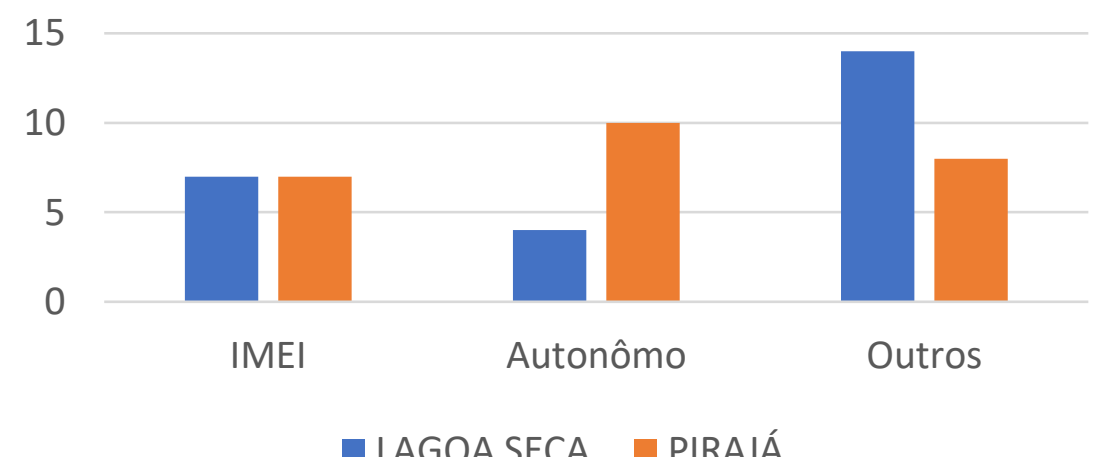

Fonte: Dados da Pesquisa (2018) 
Gráfico 4, percentual em relação à fonte de renda, com total de 14 pessoas marcaram IMEI, sendo 7 pessoas do bairro Lagoa Seca e 7 pessoas do bairro Pirajá. Outro total com 14 pessoas marcaram autônomo, sendo 4 pessoas do bairro Lagoa Seca e 10 pessoas do bairro Pirajá. Último total com 22 pessoas marcaram outros (funcionário e etc), sendo 14 pessoas do bairro Lagoa Seca e 8 pessoas do bairro Pirajá.

Gráfico 5 Tempo de estabilidade nos Bairros lagoa Seca e Pirajá.

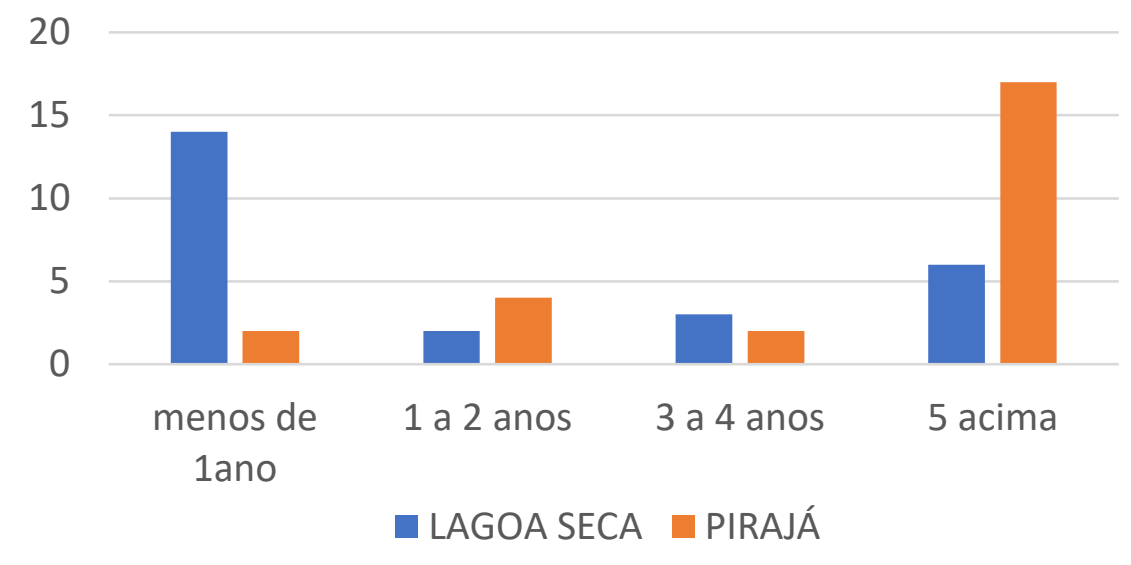

Fonte: Dados da Pesquisa (2018)

Percentual de tempo de morada em ambos os bairros. Com total de 16 pessoas marcaram em menos de 1 ano, sendo 14 pessoas do bairro Lagoa Seca e 2 do bairro Pirajá. Outro com total de 6 pessoas marcaram de 1 a 2 anos, sendo 2 pessoas do bairro Lagoa Seca e 4 pessoas do bairro Pirajá. Outro com total de 5 pessoas marcaram 3 a 4 anos, sendo 3 pessoas do bairro Lagoa Seca e 2 pessoas do bairro Pirajá. Último com total de 23 pessoas marcaram 5 anos acima, sendo 6 pessoas do bairro Lagoa Seca e 17 pessoas do bairro Pirajá.

\section{Gráfico 6 Valor pago de Energia Elétrica}

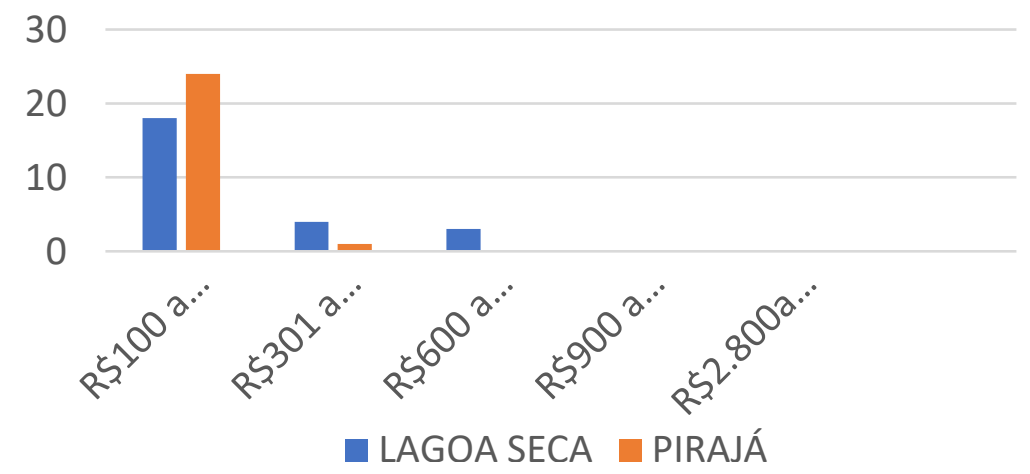

Fonte: Dados da Pesquisa (2018) 
Valor total pago de energia elétrica por cada morador, com total de 42 pessoas marcaram de $\mathrm{R} \$ 100$ a 300, sendo 18 pessoas do bairro Lagoa Seca e 24 pessoas do bairro Pirajá. Outro com total de 5 pessoas marcaram $\mathrm{R} \$$ de 301 a 500, sendo 4 pessoas do bairro Lagoa Seca e somente 1 pessoa do bairro Pirajá. Outro com total de 3 pessoas marcaram de R\$ 600 a 800, sendo 3 pessoas do bairro Lagoa Seca e não houve nenhum do bairro Pirajá. Outros valores como R \$ 900 a 1.500 e R \$ 2.800 acima não houve nenhuma pessoa.

Gráfico 7 Pergunta quanto ao conhecimento sobre recurso renovável.

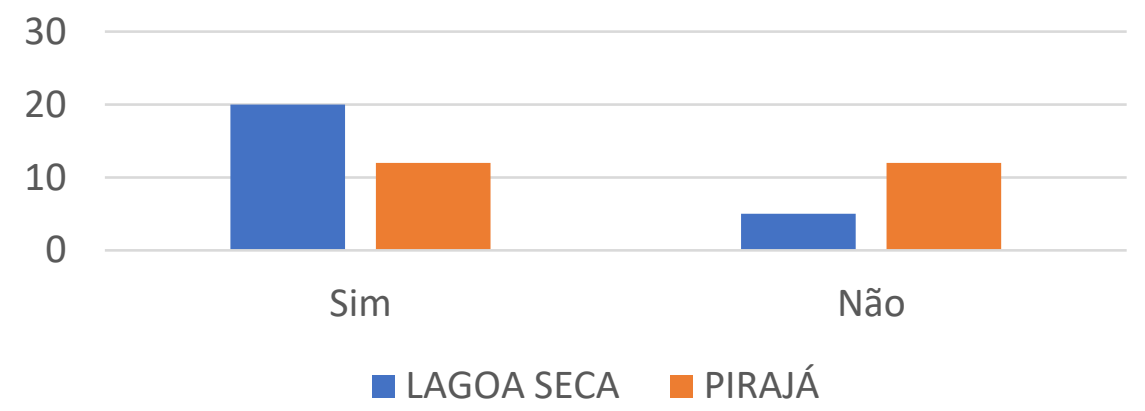

Fonte: Dados da Pesquisa (2018)

Pergunta como "Você sabe o que são recursos renováveis?", tendo com total de 32 pessoas terem marcado SIM, sendo 20 pessoas do bairro Lagoa Seca e 12 pessoas do bairro do Pirajá. Outro com total de 17 pessoas terem marcado NÃO, sendo 5 pessoas do bairro Lagoa Seca e 12 pessoas do bairro Pirajá.

Gráfico 8 Pergunta sobre a importância do uso dos recursos renováveis.

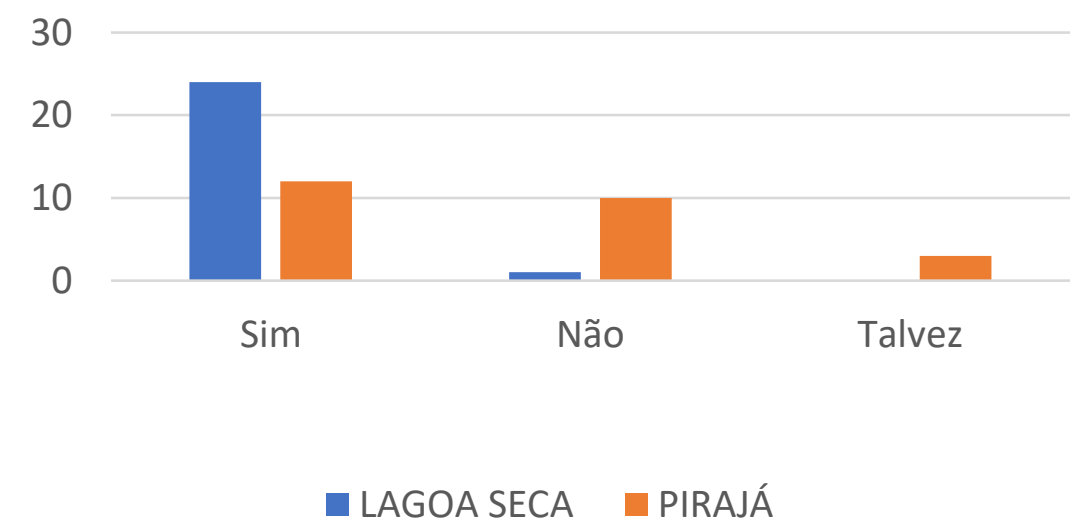

Fonte: Dados da Pesquisa (2018) 
Pergunta como "Você considera importante o uso desse recurso? ", tendo com total de 36 pessoas terem marcado SIM, sendo 24 pessoas do bairro Lagoa Seca e 12 pessoas do bairro Pirajá. Outro com total de 11 pessoas terem marcado NÃO, sendo somente 1 pessoa do bairro Lagoa Seca e 10 do bairro Pirajá. Último com total de 3 pessoas terem marcado TALVEZ, sendo 3 pessoas do bairro Pirajá e nenhuma do bairro Lagoa Seca.

Gráfico 9 Pergunta quanto ao conhecimento sobre Energia Solar.

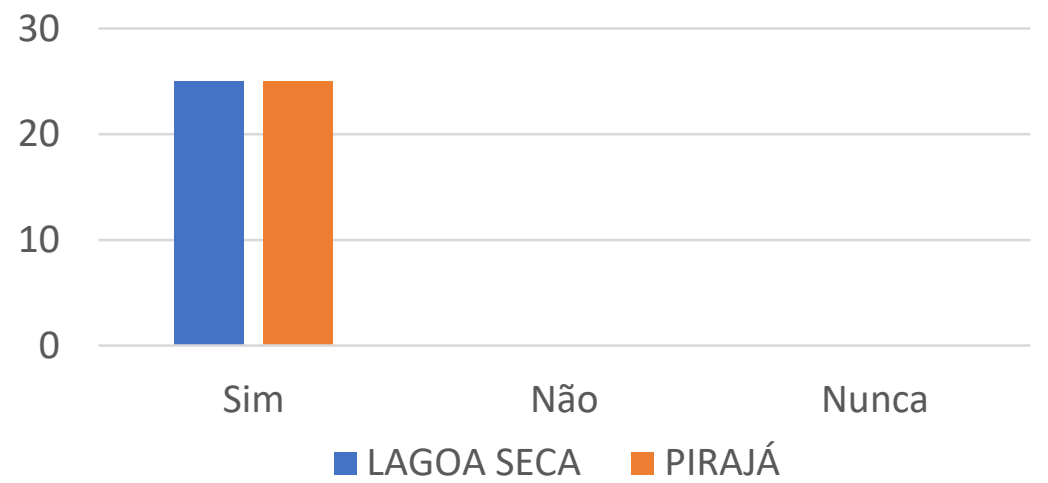

Fonte: Dados da Pesquisa (2018)

Pergunta como "Você já ouviu falar sobre Energia Solar? ", tendo com total de 50 pessoas terem marcado SIM, sendo 25 pessoas do bairro Lagoa Seca e 25 pessoas do bairro Pirajá. Outras respostas como NÃO e NUNCA não houveram nenhuma pessoa.

Gráfico 10 Pergunta sobre a importância da adesão de práticas sustentáveis.

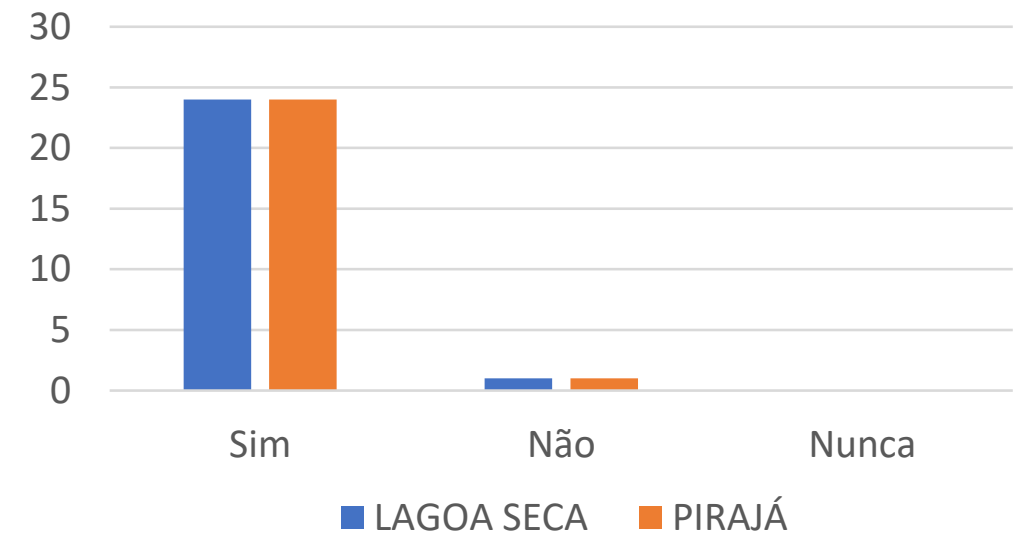

Fonte: Dados da Pesquisa (2018)

Pergunta como "Você considera importante o uso da adesão de práticas sustentáveis?", com total de 48 pessoas terem marcado SIM, sendo 24 pessoas do bairro Lagoa Seca e 24 
pessoas do bairro Pirajá. Outro com total de 2 pessoas terem marcado NÃ̃, sendo somente 1 pessoa do bairro Lagoa Seca e somente 1 pessoa do bairro Pirajá. Outra resposta como NUNCA, não houve nenhuma pessoa.

\section{Considerações Finais}

Diante do conceito sobre Sustentabilidade, destaca também sobre o uso da Energia Solar, ressaltando assim, sua importância e seus benefícios. A perspectiva desse estudo é de avaliar a percepção das pessoas quanto ao nível de conhecimento, utilização e importância do uso da Energia Solar sobre a ótica de moradores de dois bairros da Cidade de Juazeiro do NorteCE.

Porém, muitos ainda não adotam essa prática de sustentabilidade pelo fato do custo de investimento muito elevado, porém, com o passar do tempo obterá retornos significativos. Pois todo ser humano precisa se conscientizar pelo emprego das práticas sustentáveis, uma vez que os efeitos provocados contra o meio ambiente têm como consequência vários danos à saúde tanto dos indivíduos como também dos animais.

O estudo traz informações claras de forma precisa quanto a utilização da Energia Solar tanto para as empresas quanto residências, visto que ela é uma das ações sustentáveis mais propícia no combate contra o desgaste do meio ambiente, porque é renovável e não é poluente.

Contudo, a energia solar é uma ótima alternativa, pois é uma fonte renovável, inesgotável e não é poluente ao meio ambiente. Uma vez implantado, tem relevância significativa pois ajuda na conservação do meio ambiente, devido não poluir, não ajuda para o efeito estufa, além de ser indispensável na presença de geradores para a produção de energia elétrica como os sistemas heliotérmico e fotovoltaico.

\section{Referências}

ABRAMOVAY, R. Muito além da economia verde. São Paulo: Ed. Abril, 2012.

ANEEL - Agência Nacional de Energia Elétrica. Atlas de energia elétrica do Brasil. Brasília: ANEEL, 2008.

BACHA, Maria de Lourdes: Considerações teóricas sobre o conceito de Sustentabilidade. Trabalho apresentado no VII Simpósio de Excelência em Gestão e Tecnologia, 2010. 
BAIRD, Colin. Química Ambiental.Com tradução de Maria Angeles Lobo Reeio e Luiz Carlos Marques Carrera. 2 ed. Porto Alegre: Bookman, 2002.

BARBIERI, José Carlos. Gestão ambiental empresarial: conceitos, modelos e instrumentos. 3. Ed. São Paulo: Saraiva, 2011.

BERTUCCI, J. L. O. Metodologia básica para elaboração de trabalhos de conclusão de curso (TCC). São Paulo: Atlas, 2008.

CABRAL, Isabelle; VIEIRA, Rafael. Viabilidade econômica $\mathbf{x}$ viabilidade ambiental do uso de energia fotovoltaica no caso brasileiro: uma abordagem no período recente. III Congresso Brasileiro de Gestão Ambiental. 2012.

FIELD, Barry C.; FIELD, Martha K. Introdução à Economia do Meio Ambiente [recurso eletrônico]. 6. Ed. São Paulo: Mc Graw Hill Education, 2014.

JARDIM, C. S. A inserção da geração solar fotovoltaica em alimentadores urbanos enfocando a redução do pico de demanda diurno. 2007. 148 f. Tese (Doutorado em Engenharia Civil) Programa de Pós-Graduação em Engenharia Civil da Universidade Federal de Santa Catarina, Florianópolis, 2007.

LAKATOS, Eva Maria; MARCONI, Marina de Andrade. Metodologia Científica. 5. Ed. São Paulo: Atlas, 2011.

LOPES, L. F. da R. Importância da energia renovável para o meio ambiente. 2011.

MORIN, Edgar. Os sete saberes necessários à educação do futuro. 8. ed. São Paulo: Cortez, 2000.

PORTO, Laura. Energias Renováveis. Ministério de Minas e Energia: Diretora do Departamento de Desenvolvimento Energético. São Paulo, 2007.

RICHARDSON, Roberto Jarry e colaboradores. Pesquisa Social: métodos e técnicas. 3. Ed. São Paulo: Atlas, 1999.

SEVERINO, Antônio Joaquim. Metodologia do trabalho Científico. 23. Ed. rev. e atual. -São Paulo: Cortez, 2007.

VELOSO, Christiane Carvalho; AGUSTINHO, Ana Gláucia Sousa. Sustentabilidade Empresarial: estratégia das empresas inteligentes: teoria e prática. 1. Ed. Curitiba: Appris Editora, 2017.

Como citar este artigo (Formato ABNT):

SILVA, Jéssica Raissa Lima da; COSTA NETTO. Manoel Leal. Energia Solar: Análise Comparativa quanto ao Nível de Conhecimento, Utilização e Importância Sobre a Ótica de Moradores de dois bairros da Cidade de Juazeiro do Norte - CE. Id on Line Rev.Mult. Psic., 2019, vol.13, n.43, p. 416-430. ISSN: 1981-1179.

Recebido: 29/11/2018;

Aceito: $30 / 11 / 2018$ 